\title{
My Reflections on Indigeneity
}

\section{Introduction}

In this philosophical paper, I present my views on the notion of indigeneity - I relay my understanding, interpretation, and definition of "indigeneity" and justify the applicability of this definition to the New Zealand context and my experience as a practitioner. I also compare this definition with three others from different authors: Firstly, Guenther (2006) discussed the concept of indigeneity and identified two key elements including a link to a history of hunting and gathering and having a weak political position.

Secondly, McCormack (2012), reflected on the social identities study of race, nation, and culture, and discussed indigeneity as a process from the perspective of Māori claims and neoliberalism. McCormack (2012) looks at Indigeneity through various lenses: as a process intertwined with property struggles, dynamically constituted and reconstituted about the prevailing political economy, facilitated and inhibited by state organisations, and as both primordial and depending. Thirdly, Merlan (2009), looked at indigeneity from global and local perspectives. The term indigeneity, long used to distinguish between those who are native and others in specific locales, has also become a term for a social and cultural category, presupposing a world where are contrasted indigenous people to various others (Merlan, 2009). The three definitions are from different individuals with varying perspectives. In this paper, I present my understanding of indigeneity and indigenous philosophy that aligns with both my past experiences and current practice.

\section{My view on Indigeneity}

The indigenous groups associated with the word indigeneity. It means native, original or first nation. Indigeneity is a name (noun) resulting from the word 'indigene' or indigenous which describes the first nation or native people who have settled in a specific land before colonial arrival. It also refers to the native or original inhabitants of a country or area. 
In other words, indigenous people commonly regarded as being the first inhabitants of a given territory or at least, the first to have occupied the territory before successive waves of settlers (Gausset, Kenrick \& Gibb, 2011). The 'term' becomes relevant to our present day because of bloodlines resulting from ancestry. Also, it exists as an ongoing political tool, which attachment and associated with the current colonisation system - a system that promotes a political agenda that controls indigenous social and economic affairs on their land.

\section{The differences between the indigenous and non-indigenous}

The indigenous are locals and have lived on their land (which was passed on to them from their ancestry) for many years. I argue that indigeneity is about the relationship between the indigenous, their land and their environment. Therefore, indigenous people often resort to fighting for the recognition of the distinctiveness of their social, cultural, economic, and political characteristics against those of the dominant societies in which they live (Gausset et al., 2011). On the other hand, the non-indigenous often seems to arrive with a different agenda, in the form of taking away what was important and valuable to indigenous people and replacing them; for example, land, resources, culture, and languages in the name of human civilisation. The strategy with which the colonials achieve their goals against the indigenous appears to be well advanced today.

I present my perspectives and standpoint on my indigeneity. I was born in Pathwor village in South Sudan at South Upper Nile State, Malakal. I am fully Cøllø born, and both of my parents are Cøllø. My cultural identity is reflecting both visual and non-visual perspectives. The visual - The New Zealand society views me as an African because of my skin colour and ethnicity. The non-visual is my selfidentification as being Abann, the son of Kamyay Ajako and Nyakal Deng from Cøllø tribe/Iwi of South Sudan, and a New Zealand citizen. I grew up knowing my family (Whanau), tribe (Iwi), and ancestry as the Cøllø native of South Sudan. I have a beautiful life full of good and wonderful memories of my childhood. Growing up in the collective society always come with caring and sharing (Yor, 2017 p.33).

My indigeneity is in my identity and my relationship with my nuclear family, extended family, relatives, and tribe (Iwi); likewise, my connection with my homeland, Cøllø in South Sudan and New Zealand as my new home. My connection with 
my culture and language is my identity which reflects my indigeneity. Maintaining family/Whanau and tribe/Iwi relationship connected with who we are. Also, the connection and relationship a person shares with people around in his present or past are very crucial to his identity - the above explanation on my understanding of indigeneity reflected in a Māori word - whanaungatanga.

The definition in English is as follows:

Whanaungatanga a (noun) relationship, kinship, sense of family connection - a relationship through shared experiences and working together which provides people with a sense of belonging. It develops as a result of kinship rights and obligations, which also serve to strengthen each member of the kin group. It also extends to others to whom one develops a close familial, friendship or reciprocal relationship (Te Ara, 2011).

The traditional ways of doing things from my 'first nation' perspective are about sharing and caring - our culture values based on family and relative connection, relationships and kindness. I observed my people growing up as a young person. This position paper refers to my cultural context as Cøllø from the Luo family. The Luo family is the largest group in South Sudan consisting of different Iwi/tribes including Cøllø (Shilluk), Jurchol, Belanda-Boor, Thuro, Caad (shatt), Acholi, Lango, Pari (Lokoro), Anywaa (Anuak) and Burun (Nyibong, n.d). According to Nyibong (n.d), "there are also Luo in Uganda, Kenya, Tanzania, and Congo." (p.8). The Luo family is the largest group among the Nilotic stock in the continent of Africa, not just South Sudan.

It is important to understand the terminologies that others used to describe you. Names and labels in language have a potential implication for the indigenous and minority population. Before colonisation, the indigenous lived collectively as people, and they relied on their relationship with their land, nature, and environment. For instance, the indigenous people used to do things naturally; such as women (with the help of midwives) deliver their babies in naturally without any foreign medical interventions. The elders and chiefs solved issues and problems.

Most importantly, the people looked after their lands, forests, water, environment and other natural resources their way. However, the colonisation system changed everything. The 
system denied others their rights and gave others undeserved rights under the disguise of democracy.

\section{The contrast of the definition of Indigeneity}

Indigeneity is a term created by colonisation concerning indigenous people. It means native, origin or first nation. As Guenther (2006) said, "Indigenous is a term applied to people and by the people to themselves who are engaged in an often-desperate struggle for political rights for land, a place and space with a modern nation's economy and society." (p.17). According to Merlan (2009) "Indigeneity, as it expanded in its meaning to define an international category, is taken to refer to people who have great moral claims on nation-states and on international society often because of inhumane, unequal, and exclusionary treatment" (p. 304). Indigeneity and indigenous people, historically speaking, are often descendants of populations inhabiting areas that have been settled on by others. Most have been dispossessed and pushed to the fringe of resources that they once relied on (Gausset et al. 2011). As McCormack (2012) looks at indigeneity as a process, is intertwined with property struggles, dynamically constituted and reconstituted about the prevailing political economy, facilitated and inhibited by state institutions, and both primordial and contingent. Merlan (2009), as cited in Taylor, 1994), notes that while witnessing that liberalism cannot be culturally neutral. The notion of liberalism is more and less unwelcoming to the difference, and the significance of the tension and balance between recognition in terms of a universalist and egalitarian politics of equal dignity, consistent with authenticity is something we must attain if we are to be true and full human beings. "Patterns of struggles and enablement within liberal democratic environments led to the initial establishment of an international indigenous movement that is also constrained by the very dynamics that gave rise to it. Indigeneity, as it has expanded in its meaning to define an international category, is taken to refer to peoples who have great moral claims on nation-states and international society, often because of inhumane, unequal, and exclusionary treatment" (Merlan, 2009). Guenther (2006) notes “...cultural identity has become an extremely important matter. Selfrepresentation is something people expend cultural and political energy on." (p. 17).

The three authors reflected on the indigeneity associated with struggles and claiming. Indigenous people are seemingly 
gradually reclaiming what they have lost to colonisation (e.g., land). The time is right to reclaim and rebuilt what has destroyed through colonisation. New Zealand and other countries of the world are starting to realise more of what they can do for themselves and less of what others can do for them. I agree with Merlan (2009), McCormack (2012) and Guenther's (2006) perspectives on indigeneity and the indigenous, however, indigenous peoples are not just claiming and struggles, they are much more than that. As an indigenous who lost his land, families, and community, I believe indigeneity is about forgiveness as a healing process and moving on without revenge, blaming the past, finger-pointing and taking full responsibility for our future.

While we cannot change the past, we can do things differently in the present towards building a better future for the next generation to live together without racism and discrimination that was created by the past and the influence of colonisation. We can create a system that is better than the one created by the colonials, where indigenous people share and care for one another in a collective society. Our system should give every indigenous and non-indigenous the opportunity to fit in regardless of their race or background. I am aware and understand that most indigenous people are not in control of their economy and education at the moment - for example, New Zealand, Australia, Canada, and some Africa countries. The word Indigeneity for me is not just about the various definitions, but the idea and political agenda behind it are beyond these definitions. My definition of indigeneity stems from both my experience and birth as an indigenous. "The basis of definitions is also in bloodline or indigenous languages" (Gausset, Kenrick \& Gibb, 2011).

\section{Indigeneity in New Zealand Context}

The colonisation movement started with European countries establishing their empires from the $15^{\text {th }}$ to $19^{\text {th }}$ century. These countries include France, Italy, Germany, Netherlands, Denmark, Britain, Belgium, Russia, Portugal, Span, and Sweden according to Albino Deng, (personal communication 22 Sept 2018). These counties united under an umbrella because of their common interest in indigenous land and resources. The colonisation classification period came with well-developed principles of the approved act of foreign political culture seeking to dominate indigenous people. In the course of action, colonisers brought with them 
various vices including manipulation, cheating, stealing, borrowing, and hate. These vices were used to create division among indigenous people as some of them wanted the favour of the colonisers and as a result acted against their people. The strategic directions on the economy and social identities through the implementation of business initiatives that enforced missionary, military, political and media promotion to mobilise resources for their plans. The process was to establish control over indigenous lands through different deceptive frameworks such as human right and indigenous right. These frameworks never really favoured the indigenous as they are just theories and never practised rightly.

Various terms are used to describe the indigenous in different parts of the world depending on the location. For example, New Zealand commonly used Indigenous, the first nation in Canada, Aboriginal in Australia, Native in Indian North America, and African, Asian, and European continents commonly used word origin. New Zealand has a unique position geographically compared to other countries of the world, especially being a small island in the Pacific Ocean. Indigeneity in New Zealand context refers to Māoris as a first nation who have settled before the colonisers and other migrants. For instance, I am not a Māori native; I migrated from South Sudan to New Zealand as the first generation from my tribe/Iwi and Whanau/family. European were the second group of people to migrate to New Zealand; after that others joined including people like me. I consider myself an indigene of South Sudan based on my birth and my ancestry and being a migrant in New Zealand.

Sarivaara, Maatta, \& Uusiautti (2013) clarifies that,

"Significant international agreements defining the rights of indigenous peoples are the Convention no. 169 on Indigenous and Tribal Peoples by the International Labour Organization from 1989 and the United Nations Declaration on the Rights of Indigenous Peoples by the General Assembly on 13 September 2007. The ILO No. 169 convention defines such peoples indigenous whose ancestors have lived in the area before the settlement or the formation of the modern state borders. Also, the convention provides that indigenous peoples have maintained either wholly or partly their own social, economic, cultural, and political institutions. ILO no. 169 convention recognises indigenous peoples' special rights 
to their traditional residential places and natural resources and demands that states start special measures to for example protect indigenous cultures, languages, and environments. However, the convention does not take a stand on how indigenous people should be defined (ILO, 169)" (Sarivaara, Maatta, \& Uusiautti, 2013, p.370)

I am a South Sudanese, even though I am now a citizen of New Zealand, I still consider myself as a South Sudan, African indigenous. The question is; my children that are New Zealand born, can they be referred to as New Zealand indigenous? For instance, European are considered nonindigenous but some of them, their ancestry has a long history for many years. Can they be considered as second indigenous or third indigenous? For example, the Treaty of Waitangi as foundational documents for New Zealand between Māori people and Crown. The treaty is a respectful agreement containing New Zealand's shared values which every citizen and resident must respect. The principles as stated by the office of Māori Development (n.d) include:

- Partnership: The sharing of power and decision making

- Protection: The exercise of chieftainship and autonomy

- Participation: Equity of access and participation - equity of outcome.

The importance of indigeneity which I have learned in this study include, but not limited to:

Maintaining the relationship and connection between past and present generation of Māori people as the first human population to have discovered and lived in this land before anyone else. The definition of indigeneity applies to the New Zealand context because of Māori people as a first nation before colonisation 600 years ago. We cannot talk about indigeneity without talking about politics because it is a political "term" used during the colonisation era. The New Zealand Centre for Public Law (2003) defines indigeneity this way - indigenous peoples are the descendants of the first human inhabitants of the land and the descendants of those who inhabited the land at the time of European colonisation.

The Māori world view on indigeneity is unclear as Natale Coates challenged the fact the current definition of the 
indigeneity was composed of white ruling power and not by the Māori themselves (Coates, 2008). According to Coates, the definition of indigeneity should be including and take into account the perspectives and world view of indigenous groups - for instance, from a Māori perspective. And the definition should include the criterion of ethnic identity and whether the person considers himself or herself as Māori. Thus, the suggestion for the definition goes as follows; a person who has at last one Māori antecedent and who identifies himself or herself as a Māori is a Māori (Sarivaara et al. 2013; as cited in Coates, 2008).

\section{Filed of Practice}

I work in the resettlement sector where we deal with new humanitarian migration to New Zealand. These new arrivals come from different continents including Europe, Africa, Asia, and South America (Latin American countries). In this context, you may agree and disagree that these new migrants are indigenous groups regardless of their backgrounds. As I mention above indigeneity is about relationships and connection with Whanau, Iwi, Land, environment and knowing who you are. Understanding your culture and language is very important. Also, maintaining an ongoing relationship and connection with your cultural heritage and ancestry.

The indigenous communities across the modern world are still struggling under past and present colonisation systems. For example, New Zealand, Canada, North America, and Australia are still under some form of a colonisation system. Therefore, indigenous groups are still struggling for their lands and rights. However, these countries are living in peace when compared to the countries that have gained their independence from colonisation years back. For instance, some parts of Africa, Asia, Middle-East, South America and Europe are still experiencing war among themselves. The indigenous issues of the struggle for land and natural resources or the fight for rights are similar but at different levels.

Following the dark colonisation history of indigenous groups around the world, I argue that the time is right for indigenous groups to work with colonisers for a peaceful coexistence as seen in some developed countries. Eger (2017) states you can't change what happened, you can't change what done to you or what you did to others, but you can choose how to live now. We cannot change the past, but we can do 
something in the present by analysing the past and reconstructing the present towards a better future. Our responsibilities as practitioners are to prepare the next generation of indigenous groups to live in peace with equal rights and responsibilities with their non-indigenous counterparts.

\section{My practice as an indigenous person?}

I am from a disadvantaged and marginalised group in the New Zealand system after the Pacific Islanders and Māori indigenous groups of Aotearoa. According to my understanding and experience of living in New Zealand for 13 years, there is a clear misunderstanding or consensus in New Zealand about who is exactly is a migrant. For example, when we talk about migrants in New Zealand, some people refer to the Asians but the reality no one is talking about is that people from the United Kingdom, Australia, Canada, United States of America, and many other European countries are also migrants.

Furthermore, the popular belief is that the refugees in New Zealand are people from Africa and the Middle East, but the reality is that refugees come from different parts of the world through the United Nations. Therefore, it presents the general and public misunderstanding of migrants in New Zealand. As someone with an ethnic background and a part of the diaspora community in New Zealand, these factors confirm my practice as an indigenous. As Sarivaara et al. (2013) argue, "Indigenous people have their distinct languages, culture, and social and political institutions that may vary considerably from those of mainstream society" (p.375).

The Māori, Pacific Islanders and other ethnic groups in New Zealand tend to share a common human struggle due to the negative or positive impact of colonisation. Our cultures and languages have survived colonisation. Now our role is to acknowledge our ancestors for maintaining our culture, values, and language.

I work in an organisation that acts as a local and regional umbrella organisation, founded and led by new migrants from refugee backgrounds. We are a collective voice of resettled communities from ethnically diverse backgrounds. We strive to bridge the gap between our communities and service providers to achieve greater understanding, smooth resettlement, and positive integration. Currently, we bring together 22 members Incorporated society and Trusts from the resettled community and diverse backgrounds in Auckland. My 
work focuses on whanau development in resettlement and integration. My work also cuts across men, women, and youth providing capacity building and leadership training. My role as General Manager includes advocacy and leadership towards better outcomes for people for refugee backgrounds, their families, and communities; to enhance awareness, information, partnership, participation, collaboration, and improved service delivery. We promote an approach that fosters sustainability and integration, and to maintain the cultural identities of our communities so that we can thrive in our new home Aotearoa, New Zealand. We strive to bridge the gap between our communities and service providers to achieve greater understanding, smoother resettlement, and positive integration. My method takes a solutions-focused, strengthsbased, and comprehensive approach to the idea that the resettlement of newcomers and resettled families can be a positive and empowering experience. To this end, we have developed a set of values that guide our work, and these are respect, humanity, teamwork, justice, tolerance, and commitment.

Working with Whanau/family, Iwi is one of my daily life activities and dealing with issues of resettlement and integration for newcomer migrant. In this context, Māori cultural values influenced my practice. We have been the NGOs, and Government agencies described Aotearoa Resettled Community Coalition (ARCC) as a catalyst, facilitator, investigator, capacity-builder, and leader in the resettlement space. We do not deliver any services as such, but we are an advocate and provide a collective voice in the resettlement sector - our uniqueness or point of difference from other services and organisations that share the same background with us. Therefore, I see myself, from the lens of my practice, as indigenous - We (including myself) may have arrived in New Zealand as a humanitarian migrant. My country, Sudan has gained her independence from Britain since 1956 but have since been a warzone. The colonisers have physically left, but their systems and political agenda still have a strong influence on our people. Also, partly because the colonisers did not leave willingly, it resulted in a long-lasting war costing the country many lives. Since 1956, Sudan has been in a civil war between South Sudan (Christians) and the Sudan Islamic government system. Many civilians have become displaced and turned refugees in neighbouring countries. Many millions have migrated to different parts of the world including me. My 
practice as an indigenous person, where I come from and the reason I left my country this is a brief background.

\section{Conclusion}

As seen in my report, indigeneity is used to describe the first nation, native, indigenous person or aboriginal who have settled in a land before colonial arrival. For example, New Zealand, Australia, Canada, and North America are indigenous countries still operating under colonisation systems. However, some African, Middle-Eastern, Asian and European countries, even though they have gain independence for decades now are still under the influence of their colonisers. According to the United Nations (UN), claiming indigenous rights refer to countries like the United States of America, Canada, Australia, and New Zealand. Though in the $21^{\text {st }}$ century, the indigenous people in these countries are still experiencing colonisation and perhaps dictatorship and are still fighting for their indigenous rights. Indigeneity brings dark and negative memories and history of colonization because of poor treatment of indigenous groups and the forceful take over of their lands and resources. The way forward, in my view, is for indigenous peoples to develop four important institutions that give them control of their economy:

a) the first step forward is to establish educational institutions to provide the next generations with the opportunity to be equipped and be politically aware of their role to overcome ongoing indigenous struggle;

b) the second step is to establish a robust healthcare system care for the lives of indigenous people;

c) the third step is to establish proper banking and finance institutions to build an independent economic infrastructure that allows indigenous people to be controlled economically, spiritually, socially, educationally, and politically; and

d) the fourth step to establish good supermarkets to provide good and healthy food for their people.

The Colonial ideologies of race, gender, and class have constructed discourses about indigenous peoples that have served to negate the role and status of indigenous peoples in 
the Western system. The infliction of foreign government belief systems and practices arising from colonisation has served to marginalise, ignore, and redefine the world indigenous group of their values, belief, practices, and stories, for example, Māori people (Hendry et al. 2018). It is therefore vital for indigenous and non-indigenous people to work together to end human struggle and hardship collectively. Humans need one another regardless of race, gender, and backgrounds.

According to Charlie Chaplin's (1940):

"We all want to help one another. Human beings are like that. We want to live by each other's happiness - not by each other's misery. We don't want to hate and despise one another. "In this world, there's room for everyone and the good earth is rich and can provide for everyone. The way of life can be free and beautiful, but we have lost the way. Greed has poisoned men's souls - has barricaded the world with hate - has goose-stepped us into misery and bloodshed. We have developed speed, but we have shut ourselves. Machinery that gives abundance has left us in want. Our knowledge has made us cynical; our cleverness, hard and unkind. We think too much and feel too little. More than machinery we need humanity. More than cleverness, we need kindness and gentleness. Without these qualities, life will be violent, and all will be lost" (Link the Coward, 2011, May 29). 


\section{References}

Auckland Resettled Community Coalition, (2016). New Zealanders Now: from Refugees to

Kiwis.

Auckland, New Zealand: Author.

Auckland Resettled Community Coalition, (2016). Beyond Refuge: Stories of resettlement in Auckland.

Auckland, New Zealand: Author.

Eger, E. (2017). The Choice. London, England: Penguin Random House UK.

Glynn, K. (2010). Indigeneity, media and cultural globalisation; The cause of Mataku, or the Maori X-Files. International Journal of Cultural Studies. 10 (2), 205-221. http://ics.sagepub.com/.10.1177/136787790707678 8

Guenther, M. (2006). Discussion the concept of indigeneity. European Association of Anthropologists, 14(1), 17-32. https://www.researchgate.net/ 10.1017/

S0964028205001849

Hikuroa, D. (2018). Q+A: Are our indigenous communities free? Retrieved from http://www.thebigq.org/2018/08/13/are-ourindigenous-communities-really-free/

Link the Coward. (2011, May 29). The Great Dictator Speech Charlie Chaplin + Time - Hans Zimmer [The Great Dictator Speech - Charlie Chaplin]. Retrieved from https://www.youtube.com/watch?v=w8HdOHrc3OQ

Māori Development. (n.d). Introduction to the Treaty of Waitangi. Retrieved from https://www.otago.ac.nz/maori/otago667416.pdf McCormack, F. (2012). Indigeneity as process: Maori claims and neoliberalism, Social Identities, 18: 4,417434, DOI: $10.1080 / 13504630.2012 .673870$

McCormack, F. (2012). Indigeneity as a process: Maori claims and neoliberalism. Social Identities: Journal for the Study of Race, Nation, and Culture, 18/417-434. http://dx.doi.org/10.1080/13504630.2012.673870

Merlan, F. (2009). Indigeneity Global and Local. Current Anthropology, 50, 303-329. 10.1086/597667. http://www.journals.uchicago.edu/t-and-c

Moorfield, c., J. (2011). Te Aka the Online Maori Dictionary. Retrieved from http://maoridictionary.co.nz/word/10068 
Waldron, J. (2003). Indigeneity? First peoples and last occupancy. New Zealand Journal of Public and International Law, 11(1), 55-82.

Sarivaara, E, Maatta, K. \& Uusiautti, S. (2013). Who is indigenous? Definitions of indigeneity. Scientific Journal, 1, (1857 - 7881), 369-376. http://eujournal.org/index.php/esj/article/viewFile/2317 12190

Te Ara. (2011). Māori Dictionary; Whanaungatanga: Retrieved from

http://maoridictionary.co.nz/word/10068

Waldron, J. (2003). Indigeneity? First peoples and last occupancy. New Zealand Journal of Public and International Law, 11(1), 55-82.

Yor, K., A. (2017). Bench-Marking the Resettlement Process of New Zealand against Melbourne and Sydney, Australia (Winston Churchill Memorial Trust fellowship overseas trip research report). Auckland, New Zealand: Winston Churchill Memorial Trust. 